\title{
Relato de caso: Síndrome de Ramsay Hunt
}

\author{
Case report: Ramsay Hunt Syndrome \\ Reporte de caso: Síndrome de Ramsay Hunt
}

Recebido: 13/12/2021 | Revisado: 19/12/2021 | Aceito: 28/12/2021 | Publicado: 06/01/2022

Mariana Queiroz Borges

ORCID: https://orcid.org/0000-0002-0025-6132

Faculdade Alfredo Nasser, Brasil

E-mail: marianaqueirozzb@gmail.com

Daniel Mansur Caldeira

ORCID: https://orcid.org/0000-0002-4526-2202

Faculdade Alfredo Nasser, Brasil

E-mail: danielmansurc@gmail.com

Ellen Camila Rodrigues

ORCID: https://orcid.org/0000-0003-0682-3668

Faculdade Alfredo Nasser, Brasil

E-mail: Ellen_camila@yahoo.com.br

Zeno Augusto de Sousa Neto

ORCID: https://orcid.org/0000-0002-2795-4133

Faculdade Alfredo Nasser, Brasil

E-mail: zenoaugusto7@gmail.com

Mariana Resende Guedes

ORCID: https://orcid.org/0000-0002-6505-6561

Faculdade Alfredo Nasser, Brasil

E-mail: resdendemari@hotmail.com

Ábner Pereira Prado

ORCID: https://orcid.org/0000-0002-8219-6638

Faculdade Alfredo Nasser, Brasil

E-mail: aabnerprado@gmail.com

Murilo Barros-Silveira

ORCID: https://orcid.org/0000-0003-1576-2844

Universidade Federal de Goiás, Brasil

E-mail: murilo_bsilveira@hotmail.com

Aldenira Matias de Moura

ORCID: https://orcid.org/0000-0001-6213-6278 Instituto Asgard, Brasil

E-mail: aldenira110283@hotmail.com

Marcos Alexandre Diniz Carneiro

ORCID: https://orcid.org/0000-0003-3332-8865

Faculdade Alfredo Nasser, Brasil

E-mail: marcosdcarneiro@hotmail.com

\section{Resumo}

O presente estudo tem como objetivo relatar um caso de uma mulher com Síndrome de Ramsay Hunt (SRH). Paciente do gênero feminino, 39 anos, apresentou lesão vascular em pavilhão auditivo externo direito, paralisia facial periférica ipsilateral, posteriormente apresentou perda auditiva parcial em audiometria, apresentando um caso quadro clássico de SRH. Dentre os exames laboratoriais apresentou-se sorologia reagente para Herpes Simplex tipo I e II, IgG reagente e Varícela Zoster, IgM e IgG reagentes. O tratamento utilizado foi aciclovir, tenofovir e predinisona, o que levou a uma melhora parcial da paralisia facial periférica associado ao desaparecimento das lesões. O quadro apresentado demonstra a importância de um diagnóstico precoce e o tratamento feito no período correto é imprescindível para um bom prognóstico, evitando a possível presença de sequelas nervosas motoras mutiladoras.

Palavras-chave: Herpes Zoster; Paralisia facial; Síndrome de Ramsay Hunt.

\begin{abstract}
The aim of this study is to report a case of a woman with Ramsay Hunt Syndrome (SRH). Female patient, 39 years old, presenting a vascular lesion in direct external auditory pavilhão, ipsilateral peripheral facial paralysis, later presenting a partial hearing loss in audiometry, presenting a classic quadro case of SRH. Amongst the laboratory tests, reagent sorology for Herpes Simplex type I and II, reagent IgG and Varicose Zoster, IgM and IgG reagents. Either the treatment used was acyclovir, tenofovir and predinisone, or that produced a partial melt of peripheral facial paralysis associated with or disappearance of injuries. The chart presented demonstrates the importance of an early diagnosis and treatment
\end{abstract}


without a correct period and is essential for a good prognosis, avoiding the possible presence of mutilating motor nerve sequelae.

Keywords: Herpes Zoster; Facial paralysis; Ramsay Hunt Syndrome.

\section{Resumen}

El presente estudio tiene como objetivo reportar un caso de una mujer con Síndrome de Ramsay Hunt (SRH). Paciente de sexo femenino de 39 años que presentó lesión vascular en pabellón auditivo externo derecho, parálisis facial periférica ipsolateral, posteriormente con hipoacusia parcial en audiometría, presentando un caso clásico de SSR. Entre las pruebas de laboratorio, se mostraron serología de reactivo para Herpes Simplex tipo I y II, reactivo IgG y Varicela Zoster, reactivo IgM e IgG. El tratamiento utilizado fue aciclovir, tenofovir y prednisona, lo que supuso una mejoría parcial de la parálisis facial periférica asociada a la desaparición de las lesiones. El cuadro presentado demuestra la importancia de un diagnóstico precoz y el tratamiento realizado en el período correcto es fundamental para un buen pronóstico, evitando la posible presencia de secuelas mutilantes del nervio motor.

Palabras clave: Herpes Zoster; Parálisis facial; Síndrome de Ramsay Hunt.

\section{Introdução}

A síndrome de Ramsay Hunt (SRH), também conhecida como Zóster auricular é uma complicação rara de uma infecção primária por herpes-zóster em que ocorre a reativação de uma infecção latente pelo vírus Varicela-zóster (VZV) no gânglio geniculado (Murakami et al., 1998). Em 1907, James Ramsay, descreveu pela primeira vez essa síndrome caracterizada por erupções cutâneas e vesiculares no pavilhão auditivo externo, além de otalgia ipsilateral e paralisia facial periférica homolateral. Encaixa-se nesse quadro clínico também sintomas como hipoacusia, náusea, vômito, vertigem e nistagmo relacionados com o oitavo nervo craniano proximal (Rahmi, 1997; Dayan \& Peleg, 2017).

Essa síndrome é a segunda causa mais comum de paralisia facial, ficando atrás apenas da paralisia de Bell. Epidemiologia de aproximadamente 5 casos/100.000 indivíduos adultos e pacientes idosos imunossuprimidos (Gondivkar et al., 2010; Gallego et al., 2016). Apenas $10 \%$ dos pacientes com paralisia facial total recuperarão a função do nervo facial completa e somente $66 \%$ dos pacientes com paralisia incompleta recuperarão totalmente a função facial (Costa \& Veiga, 2013; Vale So et al., 2019).O objetivo desse trabalho é relatar um caso clínico de uma paciente com SRH além de uma avaliação sistêmica dessa patologia, desde seus sinais e sintomas clínicos, até a conduta terapêutica e prognóstica

\section{Metodologia}

Foi realizado um estudo analítico do tipo relato de caso, no qual se desempenhou uma análise completa de uma paciente passando pelos aspectos clínicos, sintomatológicos, físicos, laboratoriais e radiológicos.

O sigilo das informações coletadas foi mantido, somente os autores da pesquisa tiveram acesso aos dados, que foram coletados diretamente nas unidades de saúde em sala própria e com privacidade garantida, nenhuma imagem foi feita dos prontuários, o que corrobora a confidencialidade dos dados.

O estudo assim como o uso do Termo de Consentimento Livre e Esclarecido-TCLE foi submetido e aprovado pelo Comitê de Ética em Pesquisa da Faculdade Alfredo Nasser- Aparecida de Goiânia, Goiás com seres Humanos, Instituição preponente: Faculdade Alfredo Nasser - UNIFAN.CAAE:36012320.0.0000.8011. Dessa forma o trabalho está de acordo com o Conselho Nacional de Saúde (CNS) 196/96, que diz que todo trabalho envolvendo humanos direta ou indiretamente pode causar danos atuais ou tardios aos participantes. Neste caso, é um estudo indireto com seres humanos, que não causam danos, tanto no presente quanto no futuro. 


\section{Relato de Caso}

Paciente J.S.M., gênero feminino, 39 anos, natural e residente em Inhumas - Goiás, divorciada, católica, branca, apresentou-se ao atendimento médico neurológico com queixa de dor no ouvido direito e o aparecimento de lesões no pavilhão auditivo externo direito há sete dias. Relatou também, que há cinco dias, apresentou dor na articulação temporomandibular. E um dia antes de buscar o atendimento médico especializado iniciou quadro de cefaléia holocraniana, dor retro auricular moderada, além de cervicalgias difusas, e no dia da consulta a paciente apresentou raros episódios de vömito, vertigem, paralisia facial periférica a direita e queixava-se de piora do quadro de dor, além de hipoacusia após o início dos sintomas.

Ao exame físico se apresentou em regular estado geral, anictérica, acianótica e afebril, lúcida e orientada em tempo e espaço, sinais vitais preservados, analise sob os diversos sistemas sem alterações, foi verificado lesões polimórficas do tipo vesículas, pústulas e crostas no pavilhão auditivo externo direito, vertigem de caráter desequilibrante e paralisia facial periférica ipsilateral a direita como mostra nas imagens abaixo (Figura 1).

Figura 1. Caso de uma paciente com Síndrome de Ramsay Hunt.
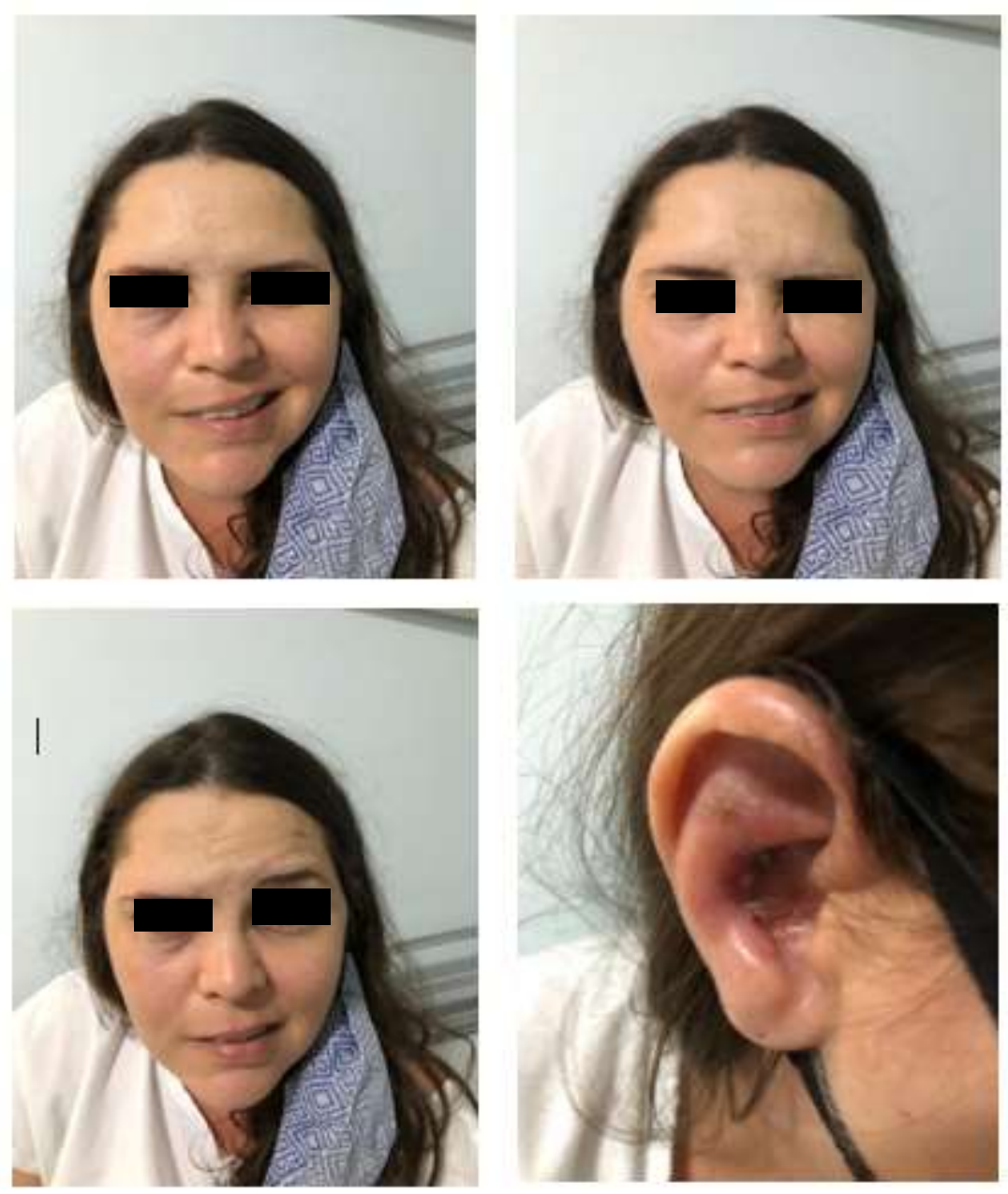

Fonte: Dados da pesquisa.

Foram solicitados exames complementares que apresentaram os seguintes resultados: No dia 20/03/2021 foi realizado: transaminase oxalacética (TGO) no valor de $22 \mathrm{U} / \mathrm{L}$, transaminase pirúvica (TGP) de $22 \mathrm{U} / \mathrm{L}$, uréia de $21 \mathrm{mg} / \mathrm{dL}$, proteína C reativa (PCR) de 7,4mg/L, sódio de 143mmol/L, potássio de 4,5 mmol/L, Creatinina de 0,7mg/dL, Hemocultura de duas amostras distintas, com resultado negativo, hemograma completo sem alterações. 
$\mathrm{Na}$ ressonância magnética de crânio apresentou um discreto favorecimento a possibilidade de um processo inflamatório/infeccioso do nervo facial direito (neurite). A associação de alterações do pavilhão auricular e do conduto auditivo externo deste lado permitem a inclusão de síndrome de Ramsay-Hunt no diagnostico diferencial. Neste mesmo dia a paciente foi hospitalizada e iniciou o tratamento farmacológico com Prednisona, Tenofovir e Aciclovir.

No dia 21/03/2021 foi realizado os seguintes exames e resultados: líquor com o aspeceto ligeiramento turvo, 25/uL de leucócitos e 13/uL de hemácias, $18 \%$ de monócitos, $84 \mathrm{mg} / \mathrm{dL}$ de glicose e $41 \mathrm{mg} / \mathrm{dL}$ de proteína, bacterioscopia do líquor com resultado negativo, lactato de 3,15mmol/L, pesquisa para fungos no líquor também foi negativa, e sorologia para Herpes Simples I e II com IgM negativo e IgG reagente. Na audiometeria a paciente apresentava curvas timpânicas tipo A, com ausência bilateral do reflexo acústico (21/03/2021). No dia 25/03/2021 foi realizado os seguintes exames e resultados: Bilirrubina total de 0,22 mg/dL, Bilirrubina direta de 0,08mg/dL, bilirrubina indireta de 0,14mg/dL, TGP de 31U/L, TGO de 16U/L, ureía de $23 \mathrm{mg} / \mathrm{dL}$, PCR de 8,6 mg/dL, Gama-GT de 22U/L, velocidade de hemossedimentação (VHS) de 35mm/h, sódio de 143mmol/L, potássio de $4,1 \mathrm{mmol} / \mathrm{L}$, Creatina de $0,7 \mathrm{mg} / \mathrm{dL}$, fosfatase alcalina de $66 \mathrm{U} / \mathrm{L}$, sorologia para Varícela Zoster com IgM reagente, e IgG reagente, hemograma completo com uma leve leucocitose derivada de monocitose..

No dia 01/04/2021 a paciente foi ao otorrinolaringologista para avaliação dos ouvidos e durante e otoscópia foi observado condutos auditivos externos assim como membranas timpânicas livres, sem alterações significativas, na audiometria tonal/focal foi evidenciado perda leve em frequências altas bilateralmente. O especialista prescreveu Betaistina $24 \mathrm{mg}$ uma vez á noite por trinta dias para o tratamento da tontura e Epitezam para proteção ocular noturna.

A paciente foi liberada para casa fazendo o uso de Predinisona $5 \mathrm{mg}$, três comprimidos por dia durante sete dias com desmame previsto, fanciclovir 500mg de oito em oito horas por sete dias, oxcarbazepina 300mg de oito em oito horas lacrima plus para região dos olhos, aciclovir creme para o pavilhão auditivo externo, Pregabalina $75 \mathrm{mg}$ de doze em doze horas. Além do tratamento não medicamentoso que inclui fisioterapia e fonoaudiologia. Após 15 dias de tratamento, a paciente apresenta melhora significativa do quadro do clínico.

\section{Discussão}

Os principais fatores de risco relatados na literatura sobre o aparecimento da síndrome de Ramsay Hunt podemos citar: o envelhecimento, o estresse emocional, o tabagismo, o diabetes, a depressão, a imunodeficiência, o câncer, o transplante de órgãos, cirurgias de forma geral, traumatismo cranioencefálico e o uso de alguns medicamentos, principalmente corticosteroides e agentes imunossupressores (Magalhães et al., 2014; Tan et al., 2020). A incidência anual de VZV é de 3,2 a 4,2 casos por 1000 habitantes. A incidência de casos aumenta na quinta década de vida e atinge o pico na oitava década, a síndrome não têm predileção por sexo, o aumento da idade está associado ao aumento na incidência (Fei et al., 2020).

O quadro clínico apresentado pela paciente como queixa de dor no ouvido direito e o aparecimento de lesões polimórficas do tipo vesículas, pústulas e crostas no pavilhão auditivo externo direito, dor na articulação temporomandibular corroboram com diversos trabalhos na literatura sobre os principais sinais e sintomas desta síndrome (Mclean et al., 2013; Magalhães et al., 2014; Paiva et al., 2017).

Para a realização do diagnóstico da SRH foi utilizado sorologias para herpes simples tipo I e II e varicela zoster, porém além disso pode ser utilizado um esfregaço Tzanck no local da lesão. Embora a cultura viral seja padrão ouro, a utilização das sorologias já foi o suficiente para fechar o diagnóstico. Pode-se utilizar para o diagnóstico mais preciso a reação em cadeia da polimerase (PCR) pois permite a identificação do genoma do VVZ, porém não pode fazer um diagnóstico com rapidez no início dos sintomas. Por isso o citodiagnóstico de Tzanck é mais útil e rápido em casos de emergência (Magalhães et al., 2014; Paiva et al., 2017; Song et al., 2018; Kim et al., 2021; Pupic-Barack et al., 2021). Além disso, a paciente realizou uma ressonância magnética de crânio que apresentou um discreto favorecimento a possibilidade de um processo inflamatório/infeccioso do nervo 
facial direito (neurite). A associação de alterações do pavilhão auricular e do conduto auditivo externo desde lado permite a inclusão de síndrome de Ramsay-Hunt no diagnostico diferencial (Donati et al., 2012; Kanerva et al., 2020). Apesar desse exame não ser critério para diagnóstico e nem o mais específico, ele é essencial para avaliar um processo infeccioso e até mesmo inflamatório do nervo para, juntamente com os exames laboratoriais para fechar o diagnóstico ou até mesmo para distinguir de outra patologia no diagnóstico diferencial (Pillar et al., 2016).

Para o tratamento é importante o uso de antiretrovirais e corticoide nas primeiras 72 horas, além das terapias não medicamentosas como: fisioterapia, acupuntura e massagens terapêuticas (Paiva et al., 2017; Orttega et al., 2018). No caso citado acima o uso de aciclovir, tenofovir e predinisona iniciou-se na admissão. A SRH deve ser diagnosticada o mais cedo possível para permitir a rápida implementação do tratamento adequado e para evitar sequelas (Magalhães et al., 2014). Apesar de um tratamento completo e adequado, ainda pode ser encontrado sequelas em cerca de $24 \%$ a $90 \%$ dos casos de SRH, e as principais complicações encontradas são: neuralgia, sincinesia, oftalmopatias, mielite segmentar e encefalite, alem da paralisia facial intensa. Pacientes com idade maior que 50 anos e que tiveram paralisia facial completa, apresentam pior prognóstico (Coulson et al., 2011; Chang, 2020).

Indivíduos que tenham tido varicela é suscetível ao SRH. Sabe-se que a síndrome não é contagiosa; todavia, a reativação do VVZ pode causar varicela em contatos que não foram previamente imunizados contra o vírus. Em imunodeficientes a infecção pode ser grave; portanto, as recomendações incluem evitar contato físico com indivíduos em fase de infecção ou que não foram vacinados, bem como com indivíduos imunodeficientes, recém-nascidos e mulheres grávidas (Paiva et al., 2017).

\section{Conclusão}

As características clínicas e os exames laboratoriais apresentados pelo caso da paciente, reforçam um caso clínico clássico da síndrome de Ramsay Hunt. O quadro apresentado demonstra a importância de um diagnóstico precoce e o tratamento feito no período correto é imprescindível para um bom prognóstico, evitando a possível presença de sequelas nervosas motoras mutiladoras.

\section{Referências}

Chang, M. C. (2020). Efficacy of pulsed radiofrequency stimulation in patients with peripheral neuropathic pain: a narrative review. Pain Physician 21(2): $225-234$.

Costa, A., \& Veiga A. (2013). Ramsay-Hunt syndrome in the differential diagnosis of stroke. Rev Soc Bras Med Trop, 46(5): 592-663.

Coulson, S., Croxson, G. R., Adams, R., Oey,V., \& Prince, P. R. (2011). Prognostic Factors in Herpes Zoster Oticus (Ramsay Hunt Syndrome ). Otol Neurotol, 32(6): 1025-1030.

Dayan, R. R., \& Peleg, R. (2017). Herpes zoster - typical and atypical presentations. Postgrad Med, 129: 567-571.

Donati, D., Santi, L., Ginanneschi, F., Cerase, A., \& Annunziata P. (2012). Successful response of non-recovering Ramsay Hunt syndrome to intravenous high dose methylprednisolone. J Neurol Sci, 318(1-2): 160-162.

Fei, Y., Deng, J., Ly, H., Yao, M., Wang, T., \& Huang B. (2020). Pulsed radiofrequency of dorsal root ganglion of upper thoracic segment for herpes zoster neuralgia: case report. Medicine, 99(4): 23-29.

Rahimi, A. R. (1998). Ramsay Hunt Syndrome: a challenging Herpes Zoster infection. Geriatrics, 53(4): 101-112.

Gallego, M. P. O. et al. (2016). Síndrome de Ramsay Hunt: a propósito de un caso. Rev Clin Med Fam, 9(2): 119-122.

Gondivkar, S., Parikh, V., \& Parikh, R. (2010). Herpes zoster oticus: a rare clinical entity. Contemp Clin Dent, 1(2): 127-129.

Kanerva, M., Jones, S., \& Pitkaranta, A. (2020). Ramsay Hunt Syndrome: Characteristics and patient self-assessed long-term fácil palsy outcome. Eur Arch Otorhinolaryngol, 277(4)? 1235-1245.

Kim, Y. S., Son, JS., Lee, H., \& Doo, A. (2021). A case reporto f refractory otalgia after Ramsay Hunt Syndorme sucessfully treated by applying pulsed radiofrequency to the great aricular nerve. Medicine, 100(39): 25-34.

Magalhães, M. J. S., Cardoso, M. S., \& Gontijo, I. L. (2014). Ramsay hunt syndrome-case report. Revneuropsiq, $18(3)$ : $247-252$. 
Research, Society and Development, v. 11, n. 1, e25611124670, 2022

(CC BY 4.0) | ISSN 2525-3409 | DOI: http://dx.doi.org/10.33448/rsd-v11i1.24670

MacLean, C. S., MD, P. H. D., \& Antonio, M. P. (2017). Ramsay Hunt Syndrome with a Cranial Nerve Polyneuropathy. Proc UCLA Healthc, 21(1): 3-12.

Murakami, S., Nakashiro, Y., Mizobuchi, M., Nato, N., \& Gyo, K. (1998). Varicela - Zoster vírus distribution in Ramsay- Hunt Syndrome revealed by polymerase chain reaction. Acta Otolaryngol (stockh), 118(2): 145-149.

Orttega, M. M. M.., et al. (2017). Síndrome de Ramsay Hunt tipo II en mujer mayor de 90 años. Rev Fac Cienc Méd, 14(2): 46-51.

Song, H. et al. (2018). Clinical Characteristics of Dizziness Associated with Acute Peripheral Facial Palsy. J Audiol Otol, 22(3): 148-153.

Paiva, A. L. C., Araujo, J. L. V., Ferraz, V. R., \& Veiga, J. C. E. (2017). Facial paralysis due to Ramsay Hunt syndrome - A rare condition. Rev Assoc Med Bras, 63(4): 301-305.

Pilar, M., Gallego, O., María, J., Angel, M., \& Armero, T. (2016). Síndrome de Ramsay Hunt. A propósito de un caso. Rev Clín Med Fam, 9(2): 119-222.

Pupic-Bakrac, J., Terkes, A., \& Baraka, I. (2021). Cranial polyneuropathy caused by herpes zoster infection: a retrospective single-center analysis. Eur Arch Otorhinolaryngol, ,278(1) :517-523.

Vale, S. O., et al. (2019). Medicina física e de reabilitação no tratamento da paralisia de Bell: qual a evidência? Rev Port Med Geral e Fam, 35(2): 116-125.

Tan, R., Yang, X.., Tang, X., Ma, W., \& He, L. (2020). The efficacy and safety of acupuncture for Ramsay Hunt Syndrome. Medicine, 99(13): 78-84. 